\title{
O instrumental didático na perspectiva de uma educação ambiental: da sensibilização à percepção ambiental
}

\section{O instrumental didático na perspectiva de uma educação ambiental: da sensibilização à percepção ambiental}

\author{
${ }^{1}$ Rosilene Rebeca rosilenerebeca@yahoo.com.br \\ 2 Ana Lúcia Crisostimo \\ ${ }^{3}$ Rosemari Monteiro Castilho Foggiatto Silveira
}

\section{RESUMO}

O objetivo deste trabalho foi verificar em que aspectos o instrumental didático utilizado em Educação Ambiental (EA) na educação básica, apresentados nos trabalhos do XV EPEA/2015 - Seção Recursos Didáticos em EA - amplificou/modificou a percepção ambiental do indivíduo em relação à mudança de comportamento frente aos problemas socioambientais, bem como estabelecer fronteiras que dificultam ou impedem avanços da EA crítica no ambiente educacional. Para tanto, o texto convida o leitor a visualizar a noção de percepção ambiental relacionada na práxis desenvolvida pelo educador nos espaços educacionais e como a educação ambiental crítica colabora para atingir este propósito. As análises foram construídas na perspectiva da pesquisa quali-quantitativa a partir da frequência do aparecimento dos termos-chave mais relevantes, apontados nos resultados e nos respectivos relatos das práticas pedagógicas, extraídos dos resumos apresentados pelos professores da educação básica ao desenvolverem atividades pedagógicas de EA. Nas análises, observou-se que a percepção e a conscientização ambiental foram alvos da maioria dos trabalhos apresentados e que a noção de percepção/conscientização foi devidamente alcançada por meio do instrumental didático. Além disso, evidenciou-se que dentre a diversidade de recursos didáticos apresentados o mais utilizado foi a oficina dialógica relacionado às condições de trabalho docente, sob uma perspectiva crítica e emancipatória. Todos os trabalhos analisados apontaram em seus resultados uma prática voltada à tríade: sensibilização, percepção e reflexão/concepção em relação às questões ambientais.

Palavras chave: Percepção Ambiental. Educação Básica. Recursos Didáticos.

\section{ABSTRACT}

The objective of this study was to analyze in which aspects of the teaching instrumental in Section Didactic Resources in Environmental Education, presented in the XV-2015 EPEA works, amplified environmental perception of the individual in relation to behavior change. To this end, the text invites the reader to visualize the concept of environmental perception related to the practice developed by the educator in educational spaces. Analyses were built from the perspective of qualitative and quantitative research from the frequency of the appearance of the most important key terms, highlighted the results and their reports of pedagogical practices, drawn from the summaries submitted by teachers of basic education in developing educational activities Environmental Education. In analyzes, it was observed that the awareness and environmental perception were the targets of most of the papers presented and the amplification of this notion of perception / awareness was duly achieved through didactic instrumental. In addition, it was observed that among the diversity of didactic resources presented the most used was the

\footnotetext{
1 Doutora em Ciências - Bioquímica pela UFPR. Professora Adjunta do Departamento de Ciências Biológicas - UNICENTRO.

2 Doutora em Educação pela UNICAMP - Professora Adjunta do Departamento de Ciências Biológicas - UNICENTRO.

3 Doutora em Educação Científica pela UFSC - Professora da UTFPR - Campus de Ponta Grossa.
} 
dialogue workshop, a fact related to the working conditions of teachers. However, all the studies analyzed showed in their results one focused practice the triad: awareness, perception and reflection / conception in relation to environmental issues.

Keywords: Environmental Perception. Basic Education. Didactic Resources.

\section{INTRODUÇÃO}

Nós que nascemos com a visão... possuindo de nascença a totalidade dos sentidos e fazendo as correlações entre eles, um com o outro, criamos um mundo visível de início, um mundo de objetos conceitos e sentidos visuais. SACKS, 1997.

Em um trecho de seu livro "Um antropólogo em Marte” Oliver Sacks afirma que, ao acordar de manhã, o ser humano vê o mundo de uma maneira passa a vida aprendendo a ver. Tudo faz sentido a partir da experiência, do toque, do se classifica e se armazena na memória, o que leva a reconhecimentos incessantes. Mesmo as conexões mais óbvias das imagens e fatos em sua volta - visual e logicamente - precisam ser apreendidas. Dessa forma, “(...) desde muito cedo o ser humano atinge a constância perceptiva - a correlação de todas as diferentes aparências, as modificações do objeto.” (SACKS, p. 141).

Assim, ao possuir de nascença a totalidade dos sentidos e ao fazer correlações entre os mesmos, um com o outro, o homem é preparado para ler o mundo, que além de visual é compreendido e impregnado de significados. Estas constatações somadas à percepção do mundo à sua volta faz com que adote, a partir do olhar, formas comportamentais adequadas ou inadequadas frente ao real. Rosa e colaboradores (2007) definem a percepção ambiental como a forma que o indivíduo ou grupo social vê, compreende e se comunica com seu meio desde a mais tenra idade. Neste trabalho adotou-se a noção de percepção ambiental proposta por Marin (2008), no que se refere ao caráter educacional, onde a percepção é parte do processo de formação do conhecimento e, por consequência da formação de valores. Assim, segundo Marin, (2008, p. 216):

(...) os objetos dos estudos sobre percepção ambiental não devem se restringir às formas como os atores sociais veem os problemas ambientais. As respostas derivadas dessa questão nos trazem formulações conceituais, muitas vezes não derivadas das vivências, das experiências perceptivas, mas de informações descontextualizadas apresentadas pela mídia. Nosso objeto é muito mais as formas com que o ser humano se mistura com o mundo, vivencia suas concretudes, se relaciona com os problemas e, coletivamente, tenta construir uma discursivida de autêntica que dê conta de exprimir seus modos de viver.

O processo ensino-aprendizagem na EA, assim como todos os campos da educação, depende fundamentalmente dos efeitos que os conceitos incorporados cognitivamente desencadeiam sobre as ações e, portanto, dependem da incorporação de novos pontos de vista, novos comportamentos culturais, sociais e individuais. Assim, não é cabível desprezar todos os setores da sociedade. O campo social está impresso na alma e no cotidiano humano. De fato, os diferentes modos como o indivíduo se relaciona com seu meio estão diretamente relacionados ao seu universo, seu ambiente com outrem e consigo mesmo, ou pelo menos da dinâmica cognitiva frente à percepção deste ambiente.

Ao escolher um recurso didático para abordar temáticas ambientais nas propostas curriculares da educação básica o que se quer é contribuir para que ocorram mudanças sociais que acarretem na melhoria na qualidade de vida das pessoas. Para tanto, o educador investe na sensibilização capaz de mudar a percepção e concepções frente à realidade socioambiental. Porém, segundo Leme (2006), é preciso considerar que só a EA "não faz milagres”. É preciso haver investimentos públicos e comprometimento pessoal, acompanhado de processos educativos. 
Neste cenário, o objetivo deste trabalho foi verificar em que aspectos o instrumental didático utilizado em EA na educação básica, apresentados nos trabalhos do XV EPEA/2015 - Seção Recursos Didáticos em EA amplificou/modificou a percepção ambiental do indivíduo em relação à mudança de comportamento frente aos problemas socioambientais. Assim como, estabelecer algumas fronteiras que dificultam ou impedem avanços da EA no ambiente educacional. Para esta reflexão, o texto convida o leitor a visualizar a noção de percepção ambiental relacionada na práxis desenvolvida pelo educador nos espaços educacionais.

\section{A PERSPECTIVA CRÍTICA DA EA NA ESCOLA}

A escola, segundo Dias (1992), é um espaço privilegiado para o desenvolvimento de ações educativas comprometidas com o ambiente. Para este autor, contudo, é imprescindível adotar ações que sejam planejadas e orientadas em projetos e ações pedagógicas que formem gerações dentro de um novo modelo de educação voltado para a sustentabilidade do planeta Terra. É necessário combater a visão de que "é natural” a ocorrência de catástrofes ambientais que afetam a humanidade, nossa cidade, nosso bairro e nossas vidas. Sob este aspecto, cabe refletir criticamente sobre a forma como nos relacionamos com o ambiente.

A educação formal constitui um dos principais canais de intervenção de EA que, segundo vários autores (DIAS, 2004; GUIMARÃES, 2006; entre outros.), permite a geração de comportamentos ambientalmente adequados. No entanto, é preciso ponderar que, na prática, o trabalho isolado do professor, por mais que seja respaldado por teorias e princípios e por um instrumental didático de EA, comumente gera resultados pontuais nos quais não é possível avaliar efetivamente às necessárias mudanças frente aos problemas ambientais, sejam eles no ambiente escolar ou na sociedade.

Assim, os caminhos da EA nos espaços escolares passam pela divulgação de culturas predatórias, alimentadas por péssimos exemplos de falta de gestão ambiental escolar e poucos investimentos do estado na rede pública de ensino. Estes fatores são agravados pela ausência de políticas educacionais de formação de educadores e a influência direta dos problemas sociais (fome, problemas de saúde pública, violência, desemprego, entre outros) que afetam direta e indiretamente a ação docente no processo ensino-aprendizagem. Estes fatores precisam ser considerados ao se propor ou avaliar a aplicabilidade e os resultados obtidos na implementação de estratégias didáticas no contexto da educação básica.

Desse cenário emerge a necessidade de se acrescentar novos princípios e metas para a implementação de um processo contínuo de ação da EA, particularmente em países emergentes como o Brasil. Apenas a obrigatoriedade de regulamentação de leis que efetivem a inserção curricular da EA em todos os níveis de ensino mascara a responsabilidade de dirigentes e formadores do sistema educacional. A crise ética, intolerância religiosa, o consumismo exacerbado e a desenfreada busca por tecnologias nem sempre sustentável são fatores que dificultam e retardam os propósitos de alicerçar comportamentos sociais construtivos, colaborando para a construção de uma sociedade socialmente justa, em um ambiente saudável. É preciso ter em mente que o ser humano levará mais de uma geração para reverter o atual quadro moral e ético que vivencia neste início de século.

Guimarães (2005, p. 193) nesta direção acrescenta:

A tendência da particularização, da individualização ao extremo chega ao individualismo exacerbado, à competição selvagem, ao sectarismo, à desigualdade, à violência, em um estado de dissolução de uma realidade conjunta, coletiva. Para se manter e existir nesta condição necessita estabelecer relações de dominação de um sobre o outro. Quando esse outro é um outro indivíduo temos o cerne da crise social, quando o outro é a natureza desvela-se a crise ambiental na sua dimensão mais ampla que engloba o social. 
Este mesmo autor acrescenta que identificar as formas hegemônicas de intervenção social é imprescindível, uma vez que. "Mantendo a lógica simplista e reducionista, concebemos o indivíduo de forma fragmentada e autônoma - isolado, sem relação, sem influência do todo”. (ibidem, 2005, p.192). Prevalece, neste caso a transmissão de conhecimentos ecologicamente corretos, centrados na educação bancária de Paulo Freire. Neste contexto, reproduz-se uma EA que em sua intervenção educacional conservadora é incapaz de tornar a sociedade mais justa e sustentável. Se a lógica da consciência ecológica individual fosse eficaz já estaríamos próximos de uma sociedade sustentável, considerando que a maioria das pessoas já possuem informações sobre a necessidade de se preservar o planeta e, no entanto, o ambiente nunca foi tão degradado como nos dias de hoje.

Acreditar na mudança dos princípios morais e que norteiam as questões ambientais requer dirigentes que pensem e regulamentem uma EA possível, aliada as rupturas socioeconômicas que viabilizem uma sociedade mais justa e inclusiva.

É preciso pontuar avanços educacionais no tocante à relação EA/educador/escola. No início da década de 1990, havia uma escassez de autores preocupados com as questões ambientais em um cenário de necessárias mudanças de conduta humana para com o planeta terra. Foram necessárias décadas para que fosse disponibilizado ao professor da educação básica, via formação inicial ou continuada, uma vasta fonte de referências sobre o conceito, marco histórico e a evolução, relevância, desafios e como trabalhar EA no contexto escolar. Esta construção histórica do conhecimento se reflete hoje na socialização de trabalhos empíricos apresentados em eventos da área ambiental dotados de uma leitura sistêmica dos problemas sociais, preocupados em apontar soluções ou minimizar os problemas e não mais na busca de levantamentos sobre concepções de meio ambiente ou na socialização de trabalhos descontextualizados que tratavam sobre questões relacionadas aos resíduos sólidos e a importância da reciclagem (como exemplo). Com a vertente crítica (LOUREIRO, 2004, 2006) a EA saiu do isolamento epistêmico e instrumentalizou o professor para uma prática docente emancipatória que leva os educandos a construírem conhecimentos e questionarem valores estabelecidos pela sociedade (GUIMARÃES, 2013).

Nesse particular, Loureiro (2004, p. 72-73) enfatiza:

A EA (...) deve metodologicamente ser realizada pela articulação dos espaços formais e não formais de educação; pela aproximação da escola à comunidade em que se insere e atende; pelo planejamento integrado de atividades curriculares e extracurriculares; pela construção coletiva e democrática do projeto político-pedagógico e pela vinculação das atividades de cunho cognitivo com as mudanças das condições objetivas de vida.

É o diálogo possível entre escola e sociedade. Diálogo entre o aparato teórico da EA com os grandes desafios humanos envoltos em temas como a manipulação genética, economia global, política, saúde pública e as grandes epidemias globais, as guerras ideológicas e as armas de destruição em massa. Assim, destaca-se o importante papel da EA ao ter como missão atuar na formação de valores sociais, individual e coletivamente via produção de conhecimentos, habilidades, atitudes e competências voltadas para a sustentabilidade ambiental, essencial à necessária qualidade de vida. É urgente investir em processos formativos críticos e emancipatórios que assumam dimensões políticas. (GUIMARÃES, 2005).

\section{O INSTRUMENTAL DIDÁTICO EM EA}

Mas afinal como desenvolver atividades pedagógicas no contexto escolar considerando diferentes realidades educacionais? Como pensar em identificar que vertente teórica da EA orienta a ação docente sem identificar lacunas e dificuldades enfrentadas na formação inicial e continuada dos mesmos? Adicionalmente a estas questões, é preciso entender que os saberes e a prática cotidiana do professor são marcados por vários fatores subjetivos: inter-relação com os alunos, gestores e outros professores que atuam em sala de aula, comprometimento com o fazer docente, conhecimento profissional advindo da prática docente. Leme (2006) acrescenta ainda a 
prática docente apresenta contradições internas: nem sempre dispõem de métodos específicos, são impregnados de valores com conotações morais e ideológicas, é baseada comumente em preceitos inconsistentes baseados na tradição de que "sempre foi assim" e finalmente, são altamente influenciadas pelo entorno socialmente hegemônico.

É ainda prudente reconhecer que muitas ações de EA são resultantes de iniciativas de professores, quase sempre desvinculadas de políticas públicas ou pensadas de maneira intuitiva e que é preciso apoiar iniciativas e socializar práticas pedagógicas como ponto de partida para a inserção de um instrumental didático de EA crítico e possível. Para tanto se faz necessário um planejamento participativo baseado na realidade social em que a escola está inserida

Assim, alguns princípios básicos norteiam uma EA que se quer participativa e crítica: envolvimento direto e indireto, sempre que possível de toda comunidade escolar, ou seja, gestores, professores, agentes administrativos, segmentos comunitários; considerar os conteúdos das disciplinas relacionadas à temática ambiental que se quer abordar (enfoque interdisciplinar), deve-se primar pela unidade teoria e a prática, o planejamento deve partir da realidade concreta e objetiva, constar no planejamento anual das áreas do conhecimento envolvidas e, quando pertinente no projeto político pedagógico da escola. (LOPES, 1990, GUIMARÃES, 2013).

\section{PERCURSO METODOLÓGICO}

Este artigo tem como campo de análise os trabalhos apresentados no XV Encontro Paranaense de EA (XV EPEA 2015), particularmente da Seção "Recursos didáticos em EA". Paralelamente ao evento ocorreu o II Colóquio Internacional de Rede de Pesquisa em EA por Bacia Hidrográfica, II Simpósio de Pesquisadores de Faxinais e III Semana do Meio Ambiente do município de Guarapuava-PR. Todos os eventos agregados ao XV EPEA tiveram como eixo norteador a discussão sobre o fortalecimento e desenvolvimento da EA no Paraná. Esses eventos têm enriquecido as discussões e oportunizado trocas de experiências sobre essa temática. Assim, o XV EPEA 2015 abrange vários segmentos sociais, além da universidade e docentes da educação básica e lideranças, também a comunidade em geral interessada em refletir e dialogar sobre os rumos e perspectivas para a melhoria das inter-relações entre os seres humanos e o ambiente.

Foram aceitos trabalhos que contemplaram resultados obtidos de experiências formativas desenvolvidas na educação básica, de graduação, pós-graduação e/ou de iniciativas e projetos dos segmentos não formais, que se enquadraram em pesquisas científicas em EA ou projetos que subsidiaram práticas e experiências na área.

Os trabalhos inscritos foram divididos nos seguintes eixos temáticos: EA nos espaços escolares; EA e políticas públicas; Fundamentos Históricos, Epistemológicos, Teórico e Metodológico em EA; Formação de educadores ambientais; EA e sustentabilidade; EA, mídias e educomunicação; EA no Campo; Redes de EA; Comunidades tradicionais: dinâmicas sociais, culturais e ambientais e Recursos didáticos em EA.

Particularmente este artigo tem como foco os 24 trabalhos aprovados no formato de resumo expandido, que se caracteriza pela elaboração de 03 a 05 páginas, da Seção "Recursos didáticos em EA”. Os relatos versam sobre experiências e investigações acerca da eficiência e viabilidade das competências e habilidades desenvolvidas pelo instrumental didático voltado à prática pedagógica da EA na sociedade. A totalidade dos trabalhos apresentados foi desenvolvida em escolas do Ensino Básico.

A leitura dos dados foi realizada por meio da análise documental tratada por Bardin (1977, p. 40). Para esta autora a análise documental ou a exploração de um banco de dados é “ 
(...) uma operação ou um conjunto de operações visando representar o conteúdo de um documento sob uma forma diferente da original, a fim de facilitar num estado ulterior a sua consulta e referenciação." Neste cenário a análise documental faz-se principalmente por classificação-indexação e por intermédio de procedimentos de transformação, tendo como objetivo, analisar e representar de forma concisa as informações provenientes dos elementos pesquisados, que permita originar um documento secundário com o máximo de informações pertinentes sobre a temática em foco. Da análise precede o acesso ao máximo de informações para que estas se tornem facilmente acessíveis ao observador. Para esta mesma autora (1977, p. 40):

esta é uma fase preliminar da constituição de um serviço de documentação ou de uma base de dados. (...). O objetivo da análise documental é a representação condensada da informação, para consulta e armazenagem; o da análise de conteúdo é a manipulação das mensagens (...) para evidenciar os indicadores que permitem inferir sobre uma outra realidade que não a da mensagem.

Os 24 resumos completos constituem o corpus documental desta pesquisa. A partir da leitura dos trabalhos, foi preenchida uma ficha individual contendo os dados institucionais, que posteriormente auxiliou na sistematização da produção investigada.

Para se identificar os conceitos frequência do aparecimento dos termos chave mais relevantes e comuns nos trabalhos apresentados, foi realizada uma busca utilizando a ferramenta de localização do word®®. Ferramenta do Microsoft Office Word, na versão 2010, que permite entre outras possibilidades, facilitar a pesquisa a documentos de forma rápida e segura. Assim, a partir desta busca foram encontrados com maior frequência os seguintes termos chave: percepção, internalização, motivação, sensibilização concepção. A leitura global dos dados possibilitaram o levantamento de unidades temáticas e a construção de 03 categorias de análise, a constar: 1) a diversidade de recursos didáticos no contexto escolar; 2) relação entre os objetivos e os resultados obtidos; 3) A educação ambiental crítica e o instrumental didático no contexto escolar, que serão na sequência apresentadas.

Para preservar a identidade dos sujeitos envolvidos nas análises da pesquisa adotaram-se as siglas R1, R2, e assim sucessivamente para as transcrições selecionadas dos documentos pesquisados.

\section{1 Categoria 1 - A diversidade de recursos didáticos no contexto escolar}

Ao observar o instrumental didático utilizado pelos professores nas ações de EA, em linhas gerais, verificou-se que nos trabalhos houve uma grande diversidade de recursos didáticos tais como a construção de hortas escolares; oficinas de materiais recicláveis; simulações, plenárias e debates; oficinas de sensibilização; uso de tecnologias de informação e comunicação (TICs) e a produção de maquetes tridimensionais. Menos frequentes foram as atividades e os projetos que fizeram uso de jogos lúdicos e material escrito como a produção de jornal e textos. Os principais recursos didáticos utilizados pelos autores podem ser agrupados em seis categorias: jogos $(n=2)$, jornal e livro $(n=2)$, google Earth $(n=4)$, oficina artística $(n=5)$, demonstração experimental $(n=4)$ e oficina dialógica $(n=7)$.

Destacam-se as oficinas dialógicas, que são atividades pedagógicas que envolvem a construção de narrativas com a participação ativa dos atores, aparecem como o principal recurso didático utilizado pelos educadores em EA. Tal fato pode ser atribuído a vários fatores, dentre os quais é possível elencar: opção metodológica adotada pelos docentes, falta de infraestrutura escolar, falta de tempo para o preparo e utilização de materiais pelos educadores, a escassez de recursos materiais exigidos para o desenvolvimento de novos instrumentais ou outros aspectos atinentes à rotina do trabalho docente. Por outro lado, ao socializar as experiências pedagógicas e elencar alguns recursos didáticos utilizados no meio educacional verificou-se que os caminhos metodológicos eleitos nos trabalhos apresentados no XV EPEA foram precedidos de um planejamento participativo aliado a 
uma prática pedagógica essencial da EA. Lembrando que ao planejar o professor articula a atividade escolar à problemática do cotidiano social.

Assim, percebeu-se que o instrumental didático em linhas gerais oportunizaram espaços de negociação de sentidos ao contemplarem atividades participativas amplamente utilizadas em EA. Garantindo, desse modo, a amplificação da percepção ambiental nos espaços educativos. Tal assertiva foi fundamentada nos resultados positivos alcançados pela grande maioria dos trabalhos apresentados.

\title{
4. 2 Categoria 2- Relação entre os objetivos e os resultados obtidos
}

Cunha e Leite (2009) avaliaram as diferenças cognitivas que se valem da percepção ambiental como signo para o entendimento das diferentes concepções acerca do ambiente. Segundo Marin (2003) a EA emergiu atrelada ao conceito de conscientização ambiental, o qual caiu em desuso pelo fato de referir-se à formação de novos conceitos fundamentada na transmissão de informações. Assim, o termo sensibilização ambiental passa a ser amplamente utilizado devido à ineficiência da transmissão de informações em gerar novos comportamentos. Os autores ainda apontam que para além da percepção, a reflexão/concepção seria o modo como a dinâmica do processo ensino-aprendizagem configuraria os comportamentos individuais e coletivos. Como ressalta Marin (2007, p. 619) "A reflexão, por sua vez, é o momento em que o ser humano procura o entendimento das suas percepções, questiona e dá forma aos significados do percebido e configura a sua relação com o mundo.” Para esta autora, a reflexão, portanto, assume um dinamismo que não seria baseado apenas na racionalidade, mas também, nos registros afetivos dos indivíduos com o seu meio.

\begin{abstract}
Não entendemos, portanto, que a sensibilização ambiental que se busca se dê, única e exclusivamente, pela via racional, pelas construções conceituais, mas através de um amplo caminho onde se cruzam imaginação, contemplação e reflexão. Os instrumentos de acesso essa via complexa precisam ser criativamente descobertos, mas acreditamos que a topofilia, a biofilia, a meditação, a interação nostálgica, o resgate das tradições, a liberdade imaginativa sejam alguns deles. (ibidem, 2007, p. 619)
\end{abstract}

Neste contexto, a dimensão afetiva da percepção atuaria de modo direto na formação de novas visões de mundo e no desenvolvimento de competências sócioemocionais. Diante deste desafio, os recursos didáticos tornam-se imprescindíveis por envolver diferentes modos de linguagem (verbal, não verbal, afetiva, emocional, entre outras.) e por tornar o universo do educando mais prazeroso e aproximado de suas vivências cotidianas.

Na análise verificou-se ainda, que, os trabalhos tiveram em comum os objetivos a serem alcançados na execução das ações de EA desenvolvidas no contexto escolar, bem como, os resultados obtidos a partir destas ações. Desta sistematização foram identificados cinco termos-chave: internalização, sensibilização, concepção, conscientização e percepção.

Em um universo de 93 localizações, por meio da ferramenta do word $\AA$, foram obtidos os seguintes percentuais para os termos: internalização (8\%), sensibilização (14\%), concepção (15\%), percepção (32\%) e conscientização (31\%). Destaca-se que a os maiores percentuais encontrados foram para os termos Percepção (32\%) e a Conscientização (31\%) como os termos-chave com maior frequência nos resumos. Isso denota que a preocupação do professor da educação básica é demonstrar que a partir da prática realizada, em uma dada realidade social, esperam-se alterações comportamentais.

Para ilustrar a categorização proposta foram selecionados e transcritos trechos contidos nos trabalhos relacionados aos termos chave frequentes, particularmente os termos percepção e conscientização, os quais foram destacados como alvo principal a ser obtido pelos educadores a partir do instrumental didático, na maioria das vezes, considerado motivador ao educando. Deste modo, optou-se por recortar os trechos mais relevantes em relação aos objetivos e resultados obtidos das ações de EA apresentadas no evento. 
Em relação aos objetivos e resultados destacam-se trechos dos resumos R1 e R4:

R1: ... a atividade de extensão visou despertá-los para uma consciência crítica em relação a esses problemas, que eles tenham a percepção, por exemplo, que não é natural lixos jogados pelas ruas, casas sem rede de esgoto, ruas em mal estado de conservação e com valetas abertas sem coleta de esgoto, terrenos baldios cobertos de lixos provocando diversos riscos.

R4: ...sendo este um evento educativo que visou estimular e promover a participação e a conscientização da classe estudantil nas questões ambientais, reconhecendo e premiando composições de canções inéditas em relação aos temas ambientais, com a finalidade de utilizar a música como ferramenta na abordagem dos conteúdos.

Depreende-se que o desenvolvimento das ações pedagógicas explicitaram o fortalecimento do processo ensino-aprendizagem por meio da amplificação da percepção/conscientização do educando para os temas trabalhados em EA.

\section{3 Categoria 03 - A educação ambiental crítica e o instrumental didático no contexto escolar}

Em alguns trabalhos apresentados no XV EPEA/2015 - Seção Recursos Didáticos em EA foi possível identificar que os preceitos da educação ambiental crítica fundamentam as estratégias de ensino adotadas em sala de aula. Esta EA crítica e emancipatória implica em que o indivíduo utilize da razão na busca de dominar comportamentos inadequados e se assuma como um indivíduo ecologicamente correto e, com o tempo, é possível vislumbrar uma nova sociedade FREIRE (2005). Tais fundamentos orientam a prática pedagógica para traduzir a importância da condução metodológica na práxis cotidiana do professor. Salienta-se o relato do professor R2:

R2: Demonstra-se, portanto a importância do emprego de jogos didáticos que versam sobre o uso racional da água como forma de desenvolver nos educandos uma percepção ambiental sobre os impactos, tanto positivos e negativos que o meio ambiente vem sofrendo pelas atividades antrópicas, estimulando a consciência ambiental e favorecendo a proliferação dos preceitos da EA crítica na sociedade.

Vale lembrar que a inserção da EA crítica é aplicável a uma dada realidade no sentido de transformá-la. Guimarães (2013, p. 40) acrescenta:

(...) que o conteúdo escolar é a apreensão sistematizada (conhecimento) de uma realidade. Se, em uma sala de aula, o educador se detiver apenas no conteúdo, não o relacionando à realidade, estará descontextualizando esse conhecimento, afastando-o da realidade concreta, tirando seu significado e alienando-o. Dessa forma, minimiza-se o conhecimento como instrumento para a prática criativa (práxis).

Neste contexto, para transpor o desafio imposto pela ciência moderna faz-se necessária uma prática docente contextualizada que alie conteúdo e o conhecimento disponível em diferentes veículos de informação, abrindo um diálogo permanente com uma abordagem crítica das questões ambientais. (LOUREIRO, 2006). Denota-se em todas as etapas da prática docente socializada nos resumos apresentados, desde o planejamento até os resultados atingidos desenvolveu a capacidade de percepção e conscientização em relação aos problemas socioambientais do lugar onde os alunos estão inseridos.

\section{CONSIDERAÇÕES FINAIS}

Ao longo desta pesquisa não foi possível especificar detalhadamente as práticas em EA descritas nos referidos trabalhos. Assim como, a descrição de particularidades inerentes às atividades que foram executadas 
em espaços diferenciados em relação à estrutura, localização geográfica, contexto histórico e cultural. Nem todos os trabalhos delinearam as etapas de planejamento da ação didática o que, inviabilizou a categorização das metodologias de ensino utilizadas.

É importante retomar questões quanto à viabilidade na execução e utilização do instrumental didático pelo professor. Na prática, sempre que o professor realizar um trabalho isolado, por mais que seja respaldado por teorias e princípios e por um instrumental didático de EA, comumente gera resultados pontuais, em que não é possível avaliar efetivamente as necessárias mudanças frente aos problemas ambientais, sejam eles no ambiente escolar ou na sociedade. Estes fatores precisam ser considerados ao se propor ou avaliar a aplicabilidade e os resultados obtidos na implementação de estratégias didáticas no contexto da educação básica.

\section{REFERÊNCIAS}

BARDIN, L. Análise de Conteúdo. Lisboa, Portugal; Edições 70, LDA, 1977.

CUNHA, A. S., LEITE, E. B. Percepção Ambiental: Implicações para a EA. Sinapse Ambiental, p. 66-79, 2009.

DIAS, G. F. Educação Ambiental: Princípios e Práticas. 3ª ed. São Paulo; Gaia, 1992.

FREITAS, O. Equipamentos e Materiais Didáticos. 1ª ed. Brasília; UnB, 2009.

GUIMARÃES, M. A dimensão ambiental na educação. Campinas, SP: Papirus. 11ª edição. 2013.

LEME, T. N. Conhecimentos práticos dos professores e sua formação continuada: um caminho para a EA na escola. In: A dimensão ambiental na educação. Da forma à ação. Campinas, SP: Papirus, 2006.

LOPES, A. O. Planejamento do ensino numa perspectiva crítica da educação. In: Repensando a didática, $4^{\mathrm{a}}$ ed. Campinas, SP: Papirus, 1990.

LOUREIRO, C., F. B. EA Transformadora. In: Identidades da EA brasileira. Ministério do Meio Ambiente. Diretoria de EA; Philippe Pomier Layrargues (Coord.). Brasília: Ministério do Meio Ambiente, 2004.

LOUREIRO, C., F. B. EA e “Teorias Críticas”. In: Caminhos da EA. Da forma à ação. GUIMARÃES, M. (Org.). Campinas, SP, 2006.

MARIN, A. A.; OLIVEIRA, H. T.; COMAR, O. A EA num contexto de complexidade do campo teórico da percepção. Interciência, v. 28 (10), p. 616-9. 2003.

MARIN, A. A. Pesquisa em EA e Percepção Ambiental. Pesquisa em EA, vol. 3, n. 1 - p. 203-222, 2008.

ROSA, L. G.; LEITE, V. D.; SILVA, M. M. P. Concepção de ambiente e EA de educadores e educadoras de uma escola de formação inicial em pedagogia nível médio. Rev. eletrônica Mestrado Educ. Ambiental. , v.18, p. 244-259, 2007.

SACKS, O. Um antropólogo em Marte. Sete histórias paradoxais. São Paulo: Cia das Letras. 1997. 